\title{
Familiarity from orthographic information: Extensions of the recognition without identification effect
}

\author{
MARIANNe E. Lloyd \\ Seton Hall University, South Orange, New Jersey \\ DEANNe L. Westerman \\ Binghamton University, Binghamton, New York
}

AND

JEREMY K. MiLLER

Willamette University, Salem, Oregon

\begin{abstract}
Two experiments were conducted to investigate the effect of letter location information in recognition memory judgments. The experiments used the recognition without identification paradigm (Peynircioğlu, 1990), in which participants first attempt to identify the test item and then make a recognition decision as to whether or not the item was studied. In these studies, items that are not identified but that correspond to items that were presented are typically still rated as more likely to have been studied than those that were not presented. The present experiments demonstrated this finding with a variant of the conjunction lure paradigm. In Experiments 1 and 2, participants were tested with word fragments that were made from the letters of two words. When the letters were from studied items, fragments were rated higher than when the test items were derived from two unstudied items, or one studied item and one unstudied item, suggesting that recognition without identification is prone to the same types of errors as recognition with identification. Results are discussed in terms of familiarity effects in recognition memory.
\end{abstract}

When reviewing the results of recognition memory experiments, a common finding is performance well above chance in situations that one might predict would lead to poor memory performance. Accurate recognition memory has been found even when the number of stimuli to be remembered is very large (e.g., Shepard, 1967; Standing, 1973), the amount of time between study and test is very long (e.g., Bahrick, 1984; Bahrick, Bahrick, \& Wittlinger, 1975; Bahrick \& Phelps, 1987; Kolers, 1976; Squire, 1989), and encoding times are very brief (e.g., Intraub, 1980). In contrast to recall, recognition memory declines little with age (e.g., Craik \& McDowd, 1987; Park, Puglisi, \& Smith, 1986; Rabinowitz, 1984; Smith, 1977), and is unaffected by divided attention tasks (e.g., Craik, Govoni, Naveh-Benjamin, \& Anderson, 1996). Perhaps an even more impressive testament to the resiliency of recognition memory, however, is that participants can discriminate between studied and novel words that cannot be identified, a finding that has been termed recognition without identification (Cleary, 2002, 2004; Cleary \& Greene, 2000, 2001; Peynircioğlu, 1990).

In experiments that have demonstrated recognition without identification, participants first study a list of words and are later given a word-fragment completion task that includes words from the study list, as well as new words. Participants are instructed to try to complete the fragment and then give a recognition rating for the stimulus on a Likert scale, whether or not they were able to solve the word fragment. Surprisingly, even when fragments cannot be solved, fragments of studied words are given higher recognition ratings than fragments of unstudied words. Such a finding is of interest, because it suggests that participants can discriminate between studied and unstudied items that they cannot complete.

Because recognition memory judgments are assumed to be based largely on the familiarity of the test items, recognition without identification has been attributed to an enhanced sense of familiarity for the fragments of studied words compared with the fragments of unstudied words (Peynircioğlu, 1990). An explanation based on enhanced familiarity has been favored over other possible explanations, such as participants' recollection of the study list, because the recognition without identification effect is not found with list discrimination and associative recognition (Cleary \& Greene, 2001; see also Cleary \& Greene, 2005), tasks that are thought to be based primarily on recollection 
(e.g., Clark \& Burchett, 1994; Westerman, 2001; Yonelinas, 1997). The enhanced familiarity for the fragments of unidentified old words does not appear to be due to perceptual overlap between studied words and their word fragments, as recognition without identification has been found even when the sensory modality of the words is changed between study and test and when the case of the letters (i.e., upper or lower case) is changed between study and test. In several recent papers on recognition without identification, Cleary and Greene (2000, 2001; Cleary, 2002) proposed that the enhanced familiarity for the fragments of studied words is based on abstract orthographic information, such as memory for the letters and their locations in words. Support for this idea can be seen in results that show a larger recognition without identification effect (a greater difference between the ratings of unidentified studied items and unidentified unstudied items) for fourletter fragments than for two-letter fragments. When more of the stimulus is reinstated, higher ratings of recognition are obtained.

Further evidence for the discrimination of unidentified studied and unstudied items being the result of memory for abstract orthographic information can be found in experiments showing a greater discrimination when fragments are shown at study and whole words appear at test (and participants are asked whether they studied a fragment of the test word) (Cleary \& Greene, 2000, Experiments $3 \mathrm{~A}$ and $3 \mathrm{~B}$ ). For example, participants rate the test item elephant higher if they studied the fragment E_E_ $\mathrm{HA}_{\text {_ }}$ than if the fragment was not presented during the study phase. The results of these experiments have been interpreted as evidence that orthographic information - in this case, the predominant type of information that was given at study-leads to enhanced feelings of familiarity for studied stimuli. That is, participants had to make their recognition ratings based on their memory of the limited information presented during the study phase.

The results of previous studies demonstrating the recognition without identification effect (Cleary, 2002; Cleary \& Greene, 2000, 2001; Peynircioğlu, 1990) can be interpreted within the framework proposed by global matching models of recognition memory (e.g., Gillund \& Shiffrin, 1984; Hintzman, 1988; Murdock, 1993; for a review, see Clark \& Gronlund, 1996). According to global matching models, the presentation of a test probe causes all of the memory representations associated with a previously studied episode to be activated, with the level of activation of each representation being a function of its similarity to the test item. To explain recognition without identification, one would assume that, in spite of the missing letters, fragments that a participant is unable to complete activate information from the study list to a greater extent when the fragments are constructed from a studied word than from an unstudied word.

Another feature of global matching models is that an item's familiarity is determined by the sum of the activation of all memory representations associated with a particular event. The present study was partially motivated by this feature of global matching models. In the experiments presented here, test words were presented as fragments.
However, in some situations the fragment was constructed from two different words from the study list rather than from one word. Because global matching models assume that familiarity is the product of the activation of all representations in memory, discrimination of fragments created from studied and unstudied items may occur, even though the fragments themselves do not correspond to one particular test word.

An additional motivation for the current study is provided by the findings of research on conjunction errors in recognition memory. Conjunction errors are high false alarm rates to new items that contain features from two different studied items. For example, a participant who studies the words chalkboard and blackbird is more likely to false alarm to blackboard, a lure constructed from two studied words, than to a lure such as blackberry or hairclip, constructed from parts of one and zero studied items, respectively (e.g., Jones, 2005; Jones \& Atchley, 2002; Jones \& Jacoby, 2001; Jones, Jacoby, \& Gellis, 2001; Reinitz, Lammers, \& Cochran, 1992; Underwood \& Zimmerman, 1973). In addition, there is recent evidence that implicit priming of these combined items may be observed in a perceptual identification task (Jones, 2004) and in errors of recall memory (Tehan \& Humphreys, 1998). One goal of the experiments presented here was to determine whether recognition without identification is prone to the same pattern of responding.

\section{EXPERIMENT 1}

In Experiment 1, test words first appeared as word fragments. Half of the fragments were constructed from two different words. Of these combination fragments, half were made from two target words and half were made from two lure words. For example, if two of the targets were the words elephant and tomorrow, the four-letter word fragment would consist of two of the letters from each word, for example, E_MP_ _ _W. Due to the nature of the stimuli used in this experiment, when the fragment included letters from two different targets, the fragments were impossible to decipher. If a sense of familiarity can come from orthographic information assessed across studied items, fragments of studied words should seem more familiar, and thus be given higher recognition ratings, than fragments of unstudied words. Therefore, the comparison of greatest interest is whether the combination items made up of studied words will seem more familiar to participants than fragments constructed from two unstudied words.

\section{Method}

Participants. Twenty-nine undergraduate students from Binghamton University participated in partial fulfillment of a course requirement.

Materials. The stimuli were 202 eight-letter words from the pool supplied by Gibson and Watkins (1988). This pool contains fragments with two critical letters filled in that limit the number of possible correct solutions to one (e.g., the fragment ${ }_{-} \mathrm{U}_{-}-_{-} \mathrm{Y}_{-}$can only be solved with the word journeys). In Experiment 1, all test fragments contained four letters and four blank spaces. Four-letter fragments for old and new words were created in a manner similar to that used by Cleary and Greene (2000). In addition to the two critical letters from the Gibson and Watkins pool, two letters were pseudo- 
randomly assigned, such that the first letter was always present (e.g., $\mathrm{J}_{-} \mathrm{U}_{-}$- EY_). To create the combination stimuli, two letters from a different word were added to the fragment provided by Gibson and Watkins (e.g., T_U_R_Y_, a combination of journeys and tomorrow). Again, because the fragments from the pool limit possible correct solutions to only one word, adding different letters from a second word made them impossible to solve. Such a manipulation guaranteed that these stimuli could not be identified.

Procedure. The recognition test contained five sequences of study and test phases. The first phase was a short practice session in which 5 words were presented, followed by a 10-item recognition test. After the practice phase, four blocks of randomly ordered study-test phases occurred. Each study phase contained 24 words and each test phase contained 32 trials, as described below.

During the study phase, words appeared one at a time on the computer screen for $2 \mathrm{sec}$. The screen was blank for $500 \mathrm{msec}$ between study items. The recognition test began immediately after the final study item was presented. During a recognition test, participants made two judgments for each fragment. First, a word fragment was presented. Participants were told to spend about $10 \mathrm{sec}$ trying to solve the fragment. They typed in their responses, which appeared on the bottom of the computer screen and were recorded. To end the fragment phase, participants pressed the Enter key. Next, a rating screen appeared containing rating instructions ("How confident are you that the fragment was a studied word?") and a scale from 1 to 9. The words sure new appeared under the number 1 and the words sure old appeared under the number 9. Participants were told to try to use as much of the scale as they saw fit. Participants rated all fragments, whether they solved the fragments or not. Between blocks, the message "Press enter to start the next list" was displayed on the screen. Participants were encouraged to take a short break before beginning a new list.

The 32 test items in each recognition test were from four categories. Eight fragments could be solved with items that were presented during the study phase (old). Eight fragments could be solved with other words that were not presented earlier (new). The other 16 fragments were made by combining two studied or unstudied items. Thus, half of the test items corresponded with words that had been presented and half did not. Participants were reminded of this fact when they were instructed on the rating task.

Participants were not told how many lists would be presented during the experiment. Block order, study list selection, and test list selection were randomly assigned across participants. The words were counterbalanced so that stimuli appeared on the study list across participants and were tested in each fragment condition (old, new, old-combination, and new-combination) with approximately equal frequency. The odd number of participants precluded groups of equal numbers.

\section{Results and Discussion}

Mean ratings as a function of condition are presented in Table 1. Incorrect solutions to the fragments ( $4.5 \%$ of responses) were not included in the analysis. A significance criterion of .05 was used in all analyses reported in this study. Participants identified more studied words (69\%) than unstudied words $(36 \%)[t(28)=11.81, S E=.03]$. Rating data was analyzed using a 2 (status: old or new) $\times$ 3 (fragment completion: completed, not completed, combination) repeated measures ANOVA. There was no effect of counterbalancing $(F<1)$. Thus, data were collapsed across counterbalancing conditions. There were main effects of status $\left[F(1,28)=199.64, M S_{\mathrm{e}}=0.28\right]$ and fragment completion $\left[F(2,56)=231.71, M S_{\mathrm{e}}=0.95\right]$. Participants gave higher ratings to old words than to new words and higher ratings to completed fragments than to fragments not completed. There was a significant interaction
Table 1

Mean Ratings for Fragments as a Function of Response Completion and Fragment Composition for Experiments 1 and 2

\begin{tabular}{lcc}
\hline & \multicolumn{2}{c}{ Fragment Completion } \\
\cline { 2 - 3 } Fragment Type & Completed & Not Completed \\
\hline Experiment 1 & 7.88 & 3.41 \\
Old & 5.04 & 3.02 \\
New & & 3.06 \\
Old-combination & & 2.88 \\
New-combination & 7.67 & \\
Experiment 2 & 4.29 & 3.02 \\
Old & & 2.70 \\
New & & 2.63 \\
Old-combination & & 2.40 \\
New-combination & & 2.51 \\
Old/new-combination & & \\
\hline
\end{tabular}

Note-Standard errors ranged from .12 to .26; combination fragments could not be completed due to the nature of the stimuli.

between status and completion $\left[F(2,56)=72.28, M S_{\mathrm{e}}=\right.$ $0.44]$. This interaction was due to greater differences in ratings for completed items than for not completed items (see Table 1). In order to test for differences in ratings between studied and unstudied items as a function of fragment completion, planned comparisons were conducted comparing the three levels of identification across status. As can be seen in Table 1, old items were rated higher than new items over each level of completion. All three of these effects were significant [completed items, $t(28)=11.63$, $S E=.24$; items not completed, $t(28)=3.36, S E=.12$; and the combination items, $t(28)=2.16, S E=.08]$.

Several important results were observed in Experiment 1 . First, discrimination between studied and unstudied items was obtained for fragments that were not completed, although the recognition without identification effect $^{1}$ was smaller than that presented in previous studies on the topic (e.g., Cleary, 2002; Cleary \& Greene, 2000, 2001; Peynircioğlu, 1990). Second, the effect occurred for fragments constructed from the parts of two studied words. The increased sense of familiarity for combination items derived from studied words suggests that the activation of orthographic information is not item specific, but rather can be activated across items. The idea of activation of familiarity from many items in a study episode is consistent with global matching models of memory, which assume that familiarity is summed across items (for a review, see Clark \& Gronlund, 1996). ${ }^{2}$

One potential concern about the recognition without identification effect is that it may be item specific; that is, because the items are identified or unidentified on the basis of participants' ability to solve the fragment, there could be something special about the unsolved set of items that makes them prone to the effect. The results of Experiment 1 argue against this interpretation, however, because a set of items was made to be unsolvable by combining two words into one fragment. The recognition without identification effect was still observed for these items, and statistical analyses suggested that the effect did not differ as a function of the set of items of which the fragments were part. Thus, it appears that the recognition without identification effect is not due to item selection 
factors. In order to support this claim, a direct item analysis is conducted in Experiment 2.

It is also possible that the results of Experiment 1 could be obtained without assuming that familiarity was assessed across items. To illustrate, again assume that a participant has studied the words journeys and tomorrow and is then presented at test with the combination fragment $J_{-} \mathrm{M}_{-}{ }_{-} \mathrm{E} \_\mathrm{W}$, which is made up of two letters from journeys and two letters from tomorrow. Fragments of this type were rated higher than fragments derived from two unstudied words, but the difference was smaller than the difference in ratings for old and new fragments made up of one studied word. We have interpreted this finding as a product of a greater study-test match in the memory trace when all of the letters come from the same word than when they come from two different words. However, the reduced discrimination for fragments made by combining two studied words could be due to the activation of one of the words of which the fragment is part. Perhaps only the letters of one of the studied words was used when making the recognition rating (for previous evidence that two letter fragments lead to a reduced recognition without identification effect, see Cleary \& Greene, 2000). In this case, the effect would be smaller, because less of the stimulus was reinstated during the test. The goal of Experiment 2 was to test this alternate interpretation of the data.

\section{EXPERIMENT 2}

In Experiment 1, all combination fragments were derived from letters from either two studied words or two unstudied words. In Experiment 2, some of the test fragments contained letters from one studied word and one unstudied word. If participants give higher ratings for fragments consisting of two studied words than for either two unstudied words or one studied and one unstudied word, we can be more confident in concluding that familiarity is being summed across studied items. If, however, the recognition without identification effect is the same for fragments derived from one old and one new word as it is for fragments containing letters from two studied words, we may conclude that the recognition without identification effect for combination items is reduced because only one of the items is being activated and the letters from a different word are being ignored.

\section{Method}

Participants. Fifty-seven undergraduates from Binghamton University participated in partial fulfillment of a course requirement.

Materials and Procedure. Experiment 2 was identical to Experiment 1 , with the following exceptions: During each test phase, six fragments each of old, new, old-combination, new-combination, and old/new-combination types were presented. In order to create old/new-combination fragments, the two letters included in the fragments from Gibson and Watkins (1988) were used for new items, and two other letters were filled in for the old item. All fragments contained the first letter of one of the two words and contained only legal combinations of letters (e.g., the fragment TX_ ON - - would not be used because TX is an illegal word onset). Because fragments in the pool rarely contain the first letter of the fragment, creating stimuli in this way ensured that the first letter nearly always came from a studied word. If the higher ratings for combination fragments of two studied words than for the ratings of combination fragments of two unstudied words is due to the familiarity of just one of the two words, it seems likely that the activated word is probably the one with the same onset letter, since some theories of visual word recognition place special emphasis on the initial letter of a word (e.g., Coltheart, Rastle, Perry, Langdon, \& Ziegler, 2001; for a similar idea in recognition memory, see Wallace, Malone, \& Spoo, 2000; Wallace, Shaffer, Amberg, \& Silvers, 2001).

\section{Results and Discussion}

Mean ratings as a function of condition are presented in Table 1. Incorrect responses (approximately $5 \%$ of all responses) were not included in the analysis. Consistent with previous experiments, participants identified more studied words $(69 \%)$ than unstudied words (34\%) $[t(56)=12.90, S E=0.03]$. Participants also displayed a recognition without identification effect, as ratings for not completed old fragments $(M=3.02)$ were higher than for new fragments not completed $(M=2.70)[t(56)=2.20$, $S E=0.15]$.

In order to test the idea that ratings for combination fragments derived from two studied words would be higher than ratings for the other types of fragments, a repeated measures ANOVA was conducted on the mean ratings of the three classes of combination fragments (old, new, and old/new). There was a significant difference among the conditions $\left[F(2,112)=6.53, M S_{\mathrm{e}}=0.78\right]$. Planned $t$ tests were conducted to explore the nature of the difference. This analysis revealed that fragments consisting of letters from two old words were rated higher than fragments containing letters from two new words $[t(56)=3.26, S E=$ $.08]$ and were rated higher than fragments containing letters from one old word and one new word $[t(56)=2.10$, $S E=.06]$. Ratings for the new fragments were not significantly different from the ratings of fragments made from one old and one new word $[t(56)=1.76, S E=.06]$. These results suggest that the discrimination between fragments of two studied items and those of two unstudied items is a product of familiarity being assessed across studied items and is not the result of two of the letters activating a studied word and the other two letters being ignored.

In order to make certain that the effects reported in Experiments 1 and 2 were not item specific, an items analysis was conducted as follows: The average rating for each word when it was a new item and when it was an old item was computed for Experiments 1 and 2. Only those words that had data for both cases were included; for example, every participant for whom the fragment for tomorrow was a studied item solved the fragment, so it was not included in the item analysis. Twenty-nine words did not meet the criterion of having ratings as both old and new items. Next, the discrimination score, obtained by subtracting the mean rating as an old item from the mean rating as a new item, was computed for each item separately for Experiments 1 and 2 . We chose first to calculate a discrimination score in order to eliminate any systematic changes in the use of the rating scale as a function of experiment. The discrimination score was then averaged across experiments. The results of the item analysis were 
similar to that by subjects. When an item was studied, it was rated significantly higher than when it was not studied $[t(162)=2.65, S E=0.13]$. The effect by items was .36, which is similar to the effect by subjects in Experiments 1 and 2 (see Table 1). Thus, it appears that the finding of increased ratings for fragments corresponding to studied items relative to those corresponding to unstudied items is not due to item-specific effects.

\section{GENERAL DISCUSSION}

The present study contributes to our understanding of how discrimination between studied and unstudied items can occur when a stimulus cannot be identified. Recognition will occur when the test probe does not correspond to any one studied word but rather contains features of two different words from the study list. In the experiments presented here, a test probe that was constructed from two studied word fragments was given higher recognition ratings than a fragment constructed from two new words (or from one old and one new word in Experiment 2), even though the word fragment was impossible to solve because it did not correspond to any word in the English language. This finding is consistent with theories of recognition memory that assume that the familiarity of a test probe is not determined by its similarity to any one item in memory, but rather that such familiarity is a function of the match between a test probe and all of the memory traces associated with a particular event (e.g., Gillund \& Shiffrin, 1984; Hintzman, 1988; Murdock, 1993; for a review, see Clark \& Gronlund, 1996).

The results of the study are reminiscent of research by Abrams and Greenwald (2000), who used a procedure in which subjects were first exposed to a list of words, were later given a new set of words, and were then asked to make fast classification judgments about the pleasantness of each word (by classifying each word as either pleasant or unpleasant). All of the classified words were immediately preceded by a prime that was either pleasant or unpleasant. The typical findings in this type of experiment show that when a pleasant test word is preceded by a pleasant prime, classification times are faster, but when the prime is negative and the test word is positive, classification times are slower (parallel effects occur when the test word is negative and the prime is either positive or negative). In Abrams and Greenwald's study, some of the primes were nonwords that were constructed by combining two words that were presented in the first phase of the experiment. For example, participants may have been exposed to the positive words tulip and humor in the first phase of the experiment. Later, they may be presented with the nonsense word hulip as a prime. Results of Abrams and Greenwald's study showed that nonwords constructed from two positive words enhanced classification judgments in the same way as the parent words from which they were constructed (and parallel effects were found when the nonwords were constructed from two negative words). The results of Experiments 1 and 2 in the present paper are similar, insofar as they show that nonword fragments constructed from two studied words can function as their parent words, and are given higher recognition ratings.

The present results expand upon the conclusions from previous work on recognition without identification. Not only can letters from one studied word lead to a sense of familiarity, so can nonwords constructed from the letters of two studied words and the letters of words not studied but related to one of the words on the study list. These results help to specify the features of a word that elicit a sense of familiarity. Certainly, other features of a word may be important in recognition memory. For example, there is evidence that the shape of a word can be used for proofreading and, more generally, for visual word recognition (Healy \& Cunningham, 1992; Monk \& Hulme, 1983). Memory for word shape may be another feature that can be used as a basis of recognition memory judgments.

We view the results of the experiments reported here as a testament to the flexibility of recognition memory. Even when a stimulus that has been previously presented cannot be identified, it is still rated as being more familiar than nonpresented items. Furthermore, recognition without identification seems prone to the same types of errors that are made when the test probe can be recognized (e.g., Jones \& Atchley, 2002; Jones \& Jacoby, 2001; Jones et al., 2001; Reinitz et al., 1992; Underwood \& Zimmerman, 1973). We believe that the recognition without identification paradigm, in addition to being a tool for specifying the type of information that can lead to a sense of familiarity, may also be useful for finding similarities among the types of information used for memorial and linguistic judgments.

\section{AUTHOR NOTE}

We thank Vaibhav Bhatia, Shauna Buckman, Jared Goodman, Nichole Greenlee, Leah Rabinowitz, Linda Rodriguez, and Dena Wolcott for assistance in testing participants. We also thank Jeffery Bowers, Todd Jones, and Elinor McKone for helpful comments on an earlier version of the manuscript. This research was supported in part by NIMH Grant 1RO3MH66156-01, which was awarded to D.L.W. Correspondence concerning this article should be sent to M. E. Lloyd, Department of Psychology, Seton Hall University, South Orange, NJ 07079 (e-mail: lloydmar@shu.edu).

Note-This article was accepted by the previous editorial team, when Colin M. MacLeod was Editor.

\section{REFERENCES}

Abrams, R. L., \& Greenwald, A. G. (2000). Parts outweigh the whole (word) in unconscious analysis of meaning. Psychological Science, 11, 118-124.

BAHRICK, H. P. (1984). Semantic memory content in permastore: Fifty years of memory for Spanish learned in school. Journal of Experimental Psychology: General, 113, 1-29.

BAHRICK, H. P., BAHRICK, P. O., \& WiTtTLINGER, R. P. (1975). Fifty years of memory for names and faces: A cross-sectional approach. Journal of Experimental Psychology: General, 104, 54-75.

BAHRICK, H. P., \& PHELPS, E. (1987). Retention of Spanish vocabulary over 8 years. Journal of Experimental Psychology: Learning, Memory, \& Cognition, 13, 344-349.

CLARK, S. E., \& BURCHETT, R. E. R. (1994). Word frequency and list composition effects in associative recognition and recall. Memory \& Cognition, 22, 55-62.

CLARK, S. E., \& GRONLUND, S. D. (1996). Global matching models of 
recognition memory: How the models match the data. Psychonomic Bulletin \& Review, 3, 37-60.

CLEARY, A. M. (2002). Recognition with and without identification: Dissociative effects of meaningful encoding. Memory \& Cognition, 30, 758-767.

CLEARY, A. M. (2004). Orthography, phonology, and meaning: Word features that give rise to feelings of familiarity in recognition. Psychonomic Bulletin \& Review, 11, 446-451.

Cleary, A. M., \& GReENE, R. L. (2000). Recognition without identification. Journal of Experimental Psychology: Learning, Memory, \& Cognition, 26, 1063-1099.

Cleary, A. M., \& Greene, R. L. (2001). Memory for unidentified items: Evidence for the use of letter information in familiarity processes. Memory \& Cognition, 29, 540-545.

Cleary, A. M., \& GreEne, R. L. (2005). Recognition without perceptual identification: A measure of familiarity? Quarterly Journal of Experimental Psychology, 58A, 1143-1152.

Coltheart, M., Rastle, K., Perry, C., Langdon, R., \& Ziegler, J. (2001). DRC: A dual route cascaded model of visual word recognition and reading aloud. Psychological Review, 108, 204-256.

Craik, F. I. M., Govoni, R., Naveh-Benjamin, M., \& Anderson, N. D. (1996). The effects of divided attention on encoding and retrieval processes in human memory. Journal of Experimental Psychology: General, 125, 159-180.

CRAIK, F. I. M., \& MCDowD, J. M. (1987). Age differences in recall and recognition. Journal of Experimental Psychology: Learning, Memory, \& Cognition, 13, 474-479.

GIBSON, J. M., \& WATKINS, M. J. (1988). A pool of 1,086 words with unique two-letter fragments. Behavior Research Methods, Instruments, \& Computers, 20, 390-397.

Gillund, G., \& Shiffrin, R. M. (1984). A retrieval model for both recognition and recall. Psychological Review, 91, 1-67.

Healy, A. F., \& Cunningham, T. F. (1992). A developmental evaluation of the role of word shape in word recognition. Memory \& Cognition, 20, 141-150.

HINTZMAN, D. L. (1988). Judgments of frequency and recognition memory in a multiple-trace model. Psychological Review, 95, 528-551.

InTRAUB, H. (1980). Presentation rate and the representation of briefly glimpsed pictures in memory. Journal of Experimental Psychology: Human Learning \& Memory, 6, 1-12.

JoNES, T. C. (2004). Perceptual specificity of priming for compound words not presented. Psychonomic Bulletin \& Review, 11, 362-366.

JONES, T. C. (2005). Study repetition and the rejection of conjunction lures. Memory, 13, 499-515.

Jones, T. C., \& ATChLEY, P. (2002). Conjunction error rates on a continuous recognition memory test: Little evidence for recollection. Journal of Experimental Psychology: Learning, Memory, \& Cognition, 28, 374-379.

JoNES, T. C., \& JACOBY, L. L. (2001). Feature and conjunction errors in recognition memory: Evidence for dual-process theory. Journal of Memory \& Language, 45, 82-102.

JoNES, T. C., JACOBY, L. L., \& GELLIS, L. A. (2001). Cross-modal feature and conjunction errors in recognition memory. Journal of Memory \& Language, 44, 131-152.

KOLERS, P. A. (1976). Reading a year later. Journal of Experimental Psychology: Human Learning \& Memory, 2, 554-565.

MonK, A. F., \& Hulme, C. (1983). Errors in proofreading: Evidence for the use of word shape in word recognition. Memory \& Cognition, 11, 16-23.

MURDOCK, B. B. (1993). TODAM2: A model for the storage and retrieval of item, associative, and serial-order information. Psychological Review, 100, 183-203.
PARK, D. C., Puglisi, J. T., \& SMith, A. D. (1986). Memory for pictures: Does an age-related decline exist? Psychology \& Aging, 1, 11-17.

PeYnirCioǦLU, Z. F. (1990). A feeling-of-recognition without identification. Journal of Memory \& Language, 29, 493-500.

Rabinowitz, J. C. (1984). Aging and recognition failure. Journal of Gerontology, 39, 65-71.

ReInitz, M. T., Lammers, W. J., \& Cochran, B. P. (1992). Memoryconjunction errors: Miscombination of stored stimulus features can produce illusions of memory. Memory \& Cognition, 20, 1-11.

SHEPARD, R. N. (1967). Recognition memory for words, sentences, and pictures. Journal of Verbal Language \& Verbal Behavior, 6, 156-163.

SMITH, A. D. (1977). Adult age differences in cued recall. Developmental Psychology, 13, 326-331.

SQUIRE, L. R. (1989). On the course of forgetting in very long-term memory. Journal of Experimental Psychology: Learning, Memory, \& Cognition, 15, 241-245.

STANDING, L. (1973). Learning 10,000 pictures. Quarterly Journal of Experimental Psychology, 25, 207-222.

TeHAN, G., \& Humphreys, M. S. (1998). Creating proactive interference in immediate recall: Building a DOG from a DART, a MOP, and a FIG. Memory \& Cognition, 26, 477-489.

UNDERWOOD, B. J., \& ZIMMERMAN, J. (1973). The syllable as a source of error in multisyllable word recognition. Journal of Verbal Learning \& Verbal Behavior, 12, 701-706.

Wallace, W. P., Malone, C. P., \& Spoo, A. D. (2000). Implicit word activation during prerecognition processing: False recognition and remember/know judgments. Psychonomic Bulletin \& Review, 7, 149-157.

WAllace, W. P., Shaffer, T. R., Amberg, M. D., \& Silvers, V. L. (2001). Divided attention and prerecognition processing of spoken words and nonwords. Memory \& Cognition, 29, 1102-1110.

Westerman, D. L. (2001). The role of familiarity in item recognition, associative recognition, and plurality recognition on self-paced and speeded tests. Journal of Experimental Psychology: Learning, Memory, \& Cognition, 27, 723-732.

YoNELINAS, A. P. (1997). Recognition memory ROCs for item and associative information: The contribution of recollection and familiarity. Memory \& Cognition, 25, 747-763.

\section{NOTES}

1. Use of the term "recognition" to describe these data may strike some as overreaching, since the ratings to all unidentified items occur on the low end of the rating scale. We use the term for two reasons: First, the key finding in all experiments is that participants show discrimination between studied and unstudied items. Second, unpublished data from our laboratory suggest that similar results may be obtained using a yes/no recognition test rather than a rating task; that is, participants endorse more unidentified studied items $(27 \%)$ than unidentified unstudied items $(12 \%)$. However, the more sensitive measure of a ratings scale is used to detect the effects described in this article.

2. It may be noted that the ratings for the combination fragments are the same as or lower than those for fragments that correspond to one unstudied word, and that this may suggest some item-specific effects of familiarity. We believe that the lower ratings are due to the overall structure of one-word versus two-word fragments. Because the two-word fragments have no solution, they should appear less wordlike and should therefore be rated as less likely to have been studied than items that do correspond to a real word.

(Manuscript received June 6, 2003; revision accepted for publication November 3, 2005.) 